\title{
AUTORIA DIGITAL DE IDOSOS: \\ A PRODUÇÃO DE INFOGRÁFICOS EM UM CURSO DE INCLUSÃO DIGITAL
}

\author{
Leticia Rocha Machado ${ }^{1}$ \\ Anna Helena Sonego² \\ Ana Carolina Ribeiro Ribeiro ${ }^{3}$ \\ Jozelina Silva da Silva Mendes ${ }^{4}$ \\ Patricia Alejandra Behar ${ }^{5}$
}

\footnotetext{
1 Graduada em Pedagogia Multimeios e Informática Educativa. Doutora em Educação. Professora visitante na Universidade Federal de Santa Catarina (UFSC), vinculada ao Programa de Pós-Graduação em Tecnologia da Informação e da Comunicação. Pesquisadora colaboradora na Universidade Federal do Rio Grande do Sul (UFRGS), no Núcleo de Tecnologia Digital Aplicada à Educação (NUTED). E-mail: leticiarmachado@gmail.com.

2 Graduada em Formação de Professores para Educação Profissional. Doutora em Educação. Pesquisadora pós-doutoranda na Universidade Federal do Rio Grande do Sul (UFRGS), no Núcleo de Tecnologia Digital Aplicada à Educação (NUTED). E-mail: sonego.anna@gmail.com.

3 Graduada em Pedagogia. Doutora em Educação. Professora na Fundação Educacional João XXIII e pesquisadora colaboradora na Universidade Federal do Rio Grande do Sul (UFRGS), no Núcleo de Tecnologia Digital Aplicada à Educação (NUTED). E-mail: carolribeiro2@gmail.com.

4 Graduada em Letras Português/Espanhol. Mestre em Educação. Pesquisadora doutoranda na Universidade Federal do Rio Grande do Sul (UFRGS), no Núcleo de Tecnologia Digital Aplicada à Educação (NUTED). E-mail: jozelinasilvadasilva@gmail.com.

5 Graduada em Informática. Doutora em Ciência da Computação. Professora Titular da Faculdade de Educação e dos cursos de Pós-Graduação em Educação (PPGEdu) e em Informática na Educação (PPGIE) da Universidade Federal do Rio Grande do Sul (UFRGS). Coordenadora do Núcleo de Tecnologia Digital Aplicada à Educação (NUTED). E-mail: pbehar@terra.com.br.
} 
resumo

Esta pesquisa tem como objetivo analisar as possíveis contribuições da autoria digital, por meio de infográficos, para um grupo de idosos participantes de um curso de inclusão digital. O envelhecimento da população e o aumento do uso das tecnologias digitais são realidades atuais. Dessa forma, percebe-se a necessidade de propor situações que permitam aos idosos a experiência frente aos recursos digitais a fim de que eles sejam incluídos tecnologicamente. A pesquisa teve uma abordagem qualitativa e quantitativa. Participaram do estudo 25 idosos de um projeto de inclusão digital realizado em uma universidade pública no sul do Brasil. Para a coleta de dados, utilizou-se um questionário contendo perguntas abertas e fechadas, observação participante e análise de infográficos construídos. Os depoimentos dos participantes viabilizaram observar uma melhoria na autoestima dos idosos pela possibilidade de desenvolver em infográficos por meio da autoria digital. A partir da análise de dados, também se observou que, apesar das dificuldades apresentadas com a utilização da ferramenta digital, a maioria dos participantes afirmou que pretende utilizar a ferramenta novamente. Tais evidências apontam que a realização desse tipo de atividade pode constituir-se em uma oportunidade de inclusão social por meio da inclusão digital.

palavras-chave

Idoso. Educação Continuada. Tecnologia Digital. Autoria. Aprendizagem.

1 Introdução

A inclusão digital de idosos apresenta-se como uma possibilidade de aprendizagem de novos conhecimentos, exploração da criatividade e desenvolvimento da autoria digital para um público que, muitas vezes, encontra-se afastado desse cenário tecnológico. De acordo com os dados divulgados pelo IBGE, o Brasil tem hoje 26 milhões de pessoas acima dos 60 anos e os estudos apontam que as estimativas para 2027 é que esse público chegará aos 37 milhões, conforme projeções do órgão (IBGE, 2017). Neste sentido, percebe-se também crescente mudança no perfil do idoso, que, anteriormente, apresentava comportamento mais isolado e menos ativo na sociedade. Atualmente, os idosos estão cada vez mais participativos e "a questão envelhecimento vem 
ganhando maior visibilidade, preocupação, discussão e estudo, pois uma nova realidade está surgindo" (FERREIRA; GOULART, 2013, p. 105). Nessa perspectiva, entende-se que o envelhecimento ativo pode contribuir para que as pessoas envelheçam com mais qualidade de vida, cultivando e desenvolvendo as relações sociais e aprimorando, cada vez mais, as suas habilidades a partir de novos aprendizados (ILC-BR, 2015).

Diante deste cenário, é importante refletir sobre a inclusão desse público na realização de diversas atividades, a fim de ampliar a sua participação social. Uma dessas possibilidades é por meio da utilização das tecnologias digitais como computadores, smartphones e tablets. Conforme Alvarenga et al. (2018), o uso de computadores costuma ser ainda o mais comum no que diz respeito ao processo de inclusão digital de idosos, embora a utilização de outras ferramentas tenha aumentado de maneira significativa. De qualquer maneira, essas "estratégias tecnológicas", denominadas pelos autores, permitem a construção de novas habilidades e a melhora do raciocínio e da memória, resultando em significativos ganhos cognitivos e sociais. Neste sentido, a partir dessas ferramentas, é possível ampliar a comunicação e instigar a produção de conteúdo e o compartilhamento de informações, já que as tecnologias digitais permitem a utilização de imagens, sons e textos, além de interação social e desenvolvimento da autoria por meio da construção de materiais digitais. Portanto, acredita-se que as tecnologias digitais podem contribuir significativamente para a qualidade de vida dos idosos (DOLL; MACHADO; CACHIONI, 2016). Loreto e Ferreira (2014) apontam que a inclusão digital de idosos permite que eles apropriem-se e façam uso da internet e demais ferramentas tecnológicas como computador, smartphones, tablets, com recursos e atividades que sejam de seu interesse e direcionados a sua faixa etária.

Conforme Rocha et al. (2016), a crescente melhora na condição de vida dos idosos propicia a constante busca por novos conhecimentos e por diferentes formas de sentirem-se mais ativos e independentes, questões, muitas vezes, viabilizadas pelo acesso à computadores e internet. Neste sentido, observa-se importância em ofertar cursos de extensão que visam à sua inclusão, em especial, aos que primam pelo desenvolvimento da autoria, tornando os idosos protagonistas de sua aprendizagem. Esses cursos oportunizam o convívio social, o compartilhamento de experiências, a realização de atividades em grupo e possibilidades de autovalorização, através do aprendizado das tecnologias digitais. Desse modo, o público idoso pode sentir-se acolhido e com potencial para vivenciar novas práticas com o uso de tecnologias digitais e, assim, ser incluído em uma sociedade considerada tecnologicamente digital (KACHAR, 2003). 
A autoria é um processo longo e contínuo que permite a elaboração de materiais em várias áreas do conhecimento. Foucault (2009) foi um dos primeiros pesquisadores que discutiram o papel do autor e da autoria. Para ele, o autor tem papel fundamental na atual sociedade, podendo ser "nomeado" (dar um nome próprio) e, assim, contribuir para ela. Cabe salientar que Foucault abordou, no seu texto, apenas o autor no contexto do discurso, não havendo uma reflexão sobre as questões tecnológicas envolvidas. No entanto, o ser humano tem potencial para estar em constante ato de criação e expressar-se de diferentes formas. Esse conceito passou a ser incluído na educação, em suas metodologias e práticas pedagógicas, já que se observou que, por meio da autoria digital, seria possível propiciar ao aluno uma ruptura paradigmática, na qual o aprendiz pudesse ser o ator principal do processo de criação e inovação no virtual. Além disso, o processo de autoria pode ser realizado em qualquer fase da vida humana com ou sem o uso de recursos tecnológicos (MENEZES, 2013).

Para Foucault (2009), os materiais, como livros e artigos, devem ser compartilhados com a sociedade em que se está ou não inserido. Neves (2016, p. 2) refere que a autoria está relacionada com "a capacidade de construir significados e de gerar projetos e conhecimentos socialmente relevantes". Assim, a autoria digital pode ser considerada a construção de todo material, como texto, imagem, sons, gráficos, infográficos, mapas, vídeos e sons que pode ser publicado através do meio digital. Nesta perspectiva, acredita-se que os idosos, quando incentivados a desenvolverem os seus próprios materiais em cursos de inclusão digital, podem apresentar conteúdos relevantes para o grupo e para sociedade. O desenvolvimento da autoria digital pode proporcionar aos idosos uma autoavaliação e autovalorização por possibilitar a expressão, percepção e experiências adquiridas ao longo da vida.

Neste sentido, os infográficos são recursos que podem ser utilizados por qualquer público para compreender um tema, assunto ou notícia, combinado com imagens, gráficos e informações de modo breve e objetivo. Conforme Costa e Tarouco (2010, p. 2), infográficos "são usados onde a informação precisa ser explicada de forma mais dinâmica, como em mapas, jornalismo e manuais técnicos, educativos ou científicos". Desse modo, um infográfico poderá transmitir conceitos e informações, sem necessidade do acompanhamento de um texto, com características visualmente atrativas e possibilitando ao leitor a compreensão de determinado tema. Para o planejamento e desenvolvimento de um infográfico, o autor deve considerar que este apresente "título, texto, corpo e fonte atentando para a construção de uma informação por meio de uma narrativa linear" (BEZERRA; SERAFIM, 2016, p. 104). 
Com base nessas características, entende-se que a realização de atividades como a construção de infográficos com idosos permite a utilização de uma nova ferramenta que visa explorar a produção do conhecimento, autoria, criatividade e criticidade com público mais velho. Portanto, os infográficos permitem "transformar dados sem sentido em informações organizadas de forma que o leitor/aluno possa entendê-las" (COSTA; TAROUCO, 2010, p. 3), ou seja, propiciam que conhecimentos sejam apresentados de forma atrativa e concisa, possibilitando aos idosos que compartilhem as suas experiências e afazeres, aproximando-os a partir de seus gostos e de suas atividades do cotidiano e trabalhando o pensamento sintético, complexo, atuando na correlação de diversos tipos de informação, ou seja, espaço, cor, forma, dados numéricos e dimensões. Entende-se, dessa forma, que a oferta de oportunidades que permita ao público mais velho a aprendizagem contínua e o compartilhamento de suas histórias pode ser fundamental para a sua inclusão na sociedade, bem como para o envelhecimento ativo. Uma dessas oportunidades é apresentada a seguir, a partir da realização de um curso de extensão.

Desse modo, avalia-se que os cursos de inclusão digital para idosos podem ser considerados como uma oportunidade que visa minimizar as distâncias e barreiras tecnológicas que podem existir entre outras faixas etárias e o público mais velho (BEHAR et al., 2010). Além disso, destaca-se que os idosos podem vivenciar sentimentos e resgatar experiências de outras etapas de sua vida, exercitando a memória e contribuindo para retomar a sua própria identidade (KACHAR, 2003). Dessa forma, acredita-se que instigar o desenvolvimento da autoria digital poderá auxiliá-los na construção da identidade, além de permitir o compartilhamento de novas situações de aprendizagem.

\section{Método}

O objetivo do estudo é analisar as contribuições da autoria digital, por meio de infográficos, para um grupo de idosos de um curso de inclusão digital. Assim sendo, a pesquisa ocorreu em um curso de extensão em uma universidade pública no Sul do Brasil. Desse modo, as atividades versaram sobre a produção de materiais digitais em forma de infográficos, abordando o tema voluntariado. A temática foi escolhida a partir do cotidiano dos participantes, o que, consequentemente, possibilitou uma maior motivação na produção de materiais para que eles se tornassem autores digitais.

Para a realização deste trabalho, foi feita uma pesquisa qualitativa e quantitativa. O público-alvo foi formado por 25 participantes com idade entre 
65 e 84 anos, alunos de um curso de extensão, realizado no segundo semestre de 2017, que visa à inclusão digital de idosos em uma universidade no sul do Brasil. O presente artigo faz parte de um projeto de mestrado que foi submetido ao comitê de ética da universidade mencionada.

Os dados foram analisados de acordo com as questões que se fizeram mais emergentes nos fragmentos (trechos) examinados e que são referentes à construção de infográficos. Desse modo, houve a necessidade de utilizar instrumentos de pesquisa como: observação participante dos pesquisadores envolvidos; utilização de um Ambiente Virtual de Aprendizagem (AVA) com ênfase para as ferramentas de fórum e webfólio (de postagem de atividades); e questionário com perguntas abertas e fechadas aplicadas no final do curso (disponível em: https://forms.gle/DnB63eujYE52LLwC7).

\subsection{Etapa 1: curso de inclusão digital com foco na autoria}

Essa etapa foi voltada para o planejamento e desenvolvimento do curso para os idosos, que foi organizado no modelo blended learning, ou seja, cinco aulas presenciais e cinco à distância. A temática escolhida foi o trabalho voluntário, tendo em vista que é uma prática presente no cotidiano na maioria dos idosos participantes. Dessa forma, além de seu interesse pela aprendizagem sobre as tecnologias digitais, a escolha deste tema poderia promover ainda mais a motivação dos participantes na exploração das ferramentas e no desenvolvimento das atividades. Durante o curso, foram realizadas as seguintes tarefas no Ambiente Virtual de Aprendizagem (AVA):

- biblioteca - disponibilização de textos como materiais de apoio e apresentações;

- ferramentas de comunicação e interação - estimulações a indagações reflexivas por meio dos recursos, fórum e contatos (mensagens);

- webfólio - compartilhamento das versões preliminares dos infográficos e, posteriormente, da versão final;

- aba aulas do AVA - foi disponibilizada uma página na internet construída pelas professoras com a ferramenta Weebly [nome do site]. Ela possuía informações sobre o curso, desenvolvimento das atividades e materiais de apoio.

O Quadro 1 mostra a organização do planejamento para a construção de infográficos pelos idosos. 
Quadro 1 - Planejamento da atividade de construção de infográficos

\begin{tabular}{|c|c|c|}
\hline \multicolumn{3}{|c|}{ Nome do curso: Construindo infográficos } \\
\hline \multicolumn{3}{|c|}{$\begin{array}{l}\text { Objetivos: construção de um infográfico utilizando a ferramenta Easel. ly (ferramenta na língua } \\
\text { inglesa). }\end{array}$} \\
\hline \multicolumn{3}{|c|}{$\begin{array}{l}\text { Recursos necessários: } \\
\text { - } \quad \text { laboratório de informática com acesso à internet (um computador por aluno); } \\
\text { - } \quad \text { computador com projetor; } \\
\text { - } \quad \text { videoaulas, apresentação em ppt, pesquisa na internet e fórum de discussão; } \\
\text { - } \quad \text { ferramenta Easel.ly para construção de infográficos, com versão gratuita e em inglês, dispo- } \\
\text { - } \quad \text { sível em wnw.easel.ly/; } \\
\text { - } \quad \text { exemplos de infográficos coletados na internet; } \\
\text { - tutorial sobre a ferramenta Easel.ly. }\end{array}$} \\
\hline \multicolumn{3}{|c|}{$\begin{array}{l}\text { Carga horária sugerida: } 10 \mathrm{~h} \text { presenciais e } 10 \mathrm{~h} \text { para a realização de atividades em casa ( } 4 \mathrm{~h} \text { po } \\
\text { semana, duas presenciais e duas à distância, distribuídas em cinco semanas). }\end{array}$} \\
\hline Aula & Assunto da aula presencial & Atividade virtual \\
\hline 1 & O que é um infográfico? & Definição do assunto do infográfico \\
\hline 2 & Planejamento do infográfico & Elaboração de esboço \\
\hline 3 & $\begin{array}{l}\text { Pesquisando imagens e construindo seu } \\
\text { infográfico com a ferramenta Easel.ly. }\end{array}$ & $\begin{array}{l}\text { Construção do infográfico com a } \\
\text { ferramenta }\end{array}$ \\
\hline 4 & Produção do infográfico & Continuação do infográfico \\
\hline 5 & Finalização do infográfico & Postagem no Webfólio \\
\hline
\end{tabular}

Fonte: Elaborado pelas autoras (2019).

Após o término do curso, foi aplicado um questionário com três perguntas abertas e fechadas, no qual foi possível analisar possíveis contribuições do desenvolvimento da autoria digital para os idosos.

\subsection{Etapa 2: análise e discussão dos dados}

Essa etapa foi destinada para a análise e discussão dos dados coletados. Para a análise dos dados, utilizou-se o método de análise de conteúdo de Bardin (2010), que abrange as etapas de pró-análise, correspondente à organização do material coletado e da formulação de hipóteses; leitura exploratória do material, consistindo na análise dos materiais obtidos. Por fim, é obtido o tratamento dos dados, através da análise dos mesmos. 


\section{Resultados}

Na pesquisa, participaram um total de 25 idosos. O público era composto, em sua grande maioria, por mulheres $(80 \%)$, com média de 71,04 anos de idade. Os resultados são os seguintes: (40\%) concluiu o ensino médio e $72 \%$ afirmaram que nunca tinha visto um infográfico. Além disso, $82 \%$ não conheciam a ferramenta Easel.ly, utilizada para a construção dos materiais (infográficos). Outro dado importante é a quantidade de idosos que realizava trabalho voluntário, sendo $10 \%$ do total dos participantes. O perfil verificado é de um público mais velho com escolaridade alta, comparada ao perfil do idoso brasileiro e com pouco ou nenhum conhecimento sobre a ferramenta apresentada. Portanto, são idosos com características distintas que devem ser consideradas ao analisar os dados apresentados.

Conforme Costa e Tarouco (2010), os infográficos proporcionam informações sucintas, facilitando a compreensão dos conteúdos abordados. Dessa forma, durante as aulas, observou-se que os idosos demonstraram bastante interesse em aprendera produção de infográficos, pois consideram um formato interessante para a organização e divulgação dos temas materiais desenvolvidos. Neste sentido, na primeira aula, eles puderam refletir sobre o conceito de infográfico, além de analisar alguns exemplos e discutir sobre os formatos mais adequados, considerando questões relacionadas ao design no uso de cores e fontes nos exemplos vistos.

Posteriormente, os participantes desenvolveram um esboço do seu infográfico em papel, com o intuito de selecionar as informações que desejavam utilizar, além das cores adequadas e organização da disposição dos conteúdos. No entanto, também foi realizada uma pesquisa por imagens, em bancos de imagens gratuitas, além da captação de fotos com a câmera do smartphone. Após a elaboração do esboço, os idosos aprenderam a utilização da ferramenta Easel.ly, explorando as possibilidades de uso e os templates disponíveis. Na sequência, os participantes construíram o seu infográfico de forma digital. A Figura 1 apresenta um esboço de um infográfico e a versão final. 

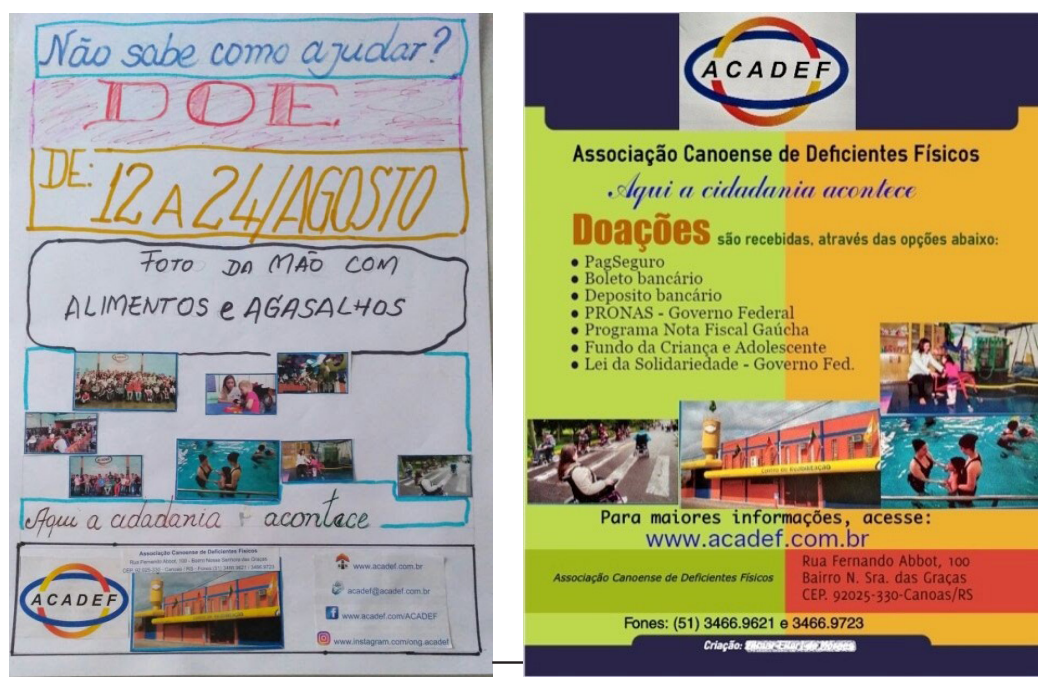

Fonte: Acervo das autoras (2018).

Após o desenvolvimento do curso, aplicou-se um questionário para compreender o processo de autoria digital dos participantes, levando em conta que essa autoria deve estar relacionada com a elaboração e criação de significados e conhecimentos (NEVES, 2016). Inicialmente, foi indagado sobre o uso da ferramenta de construção de infográfico e os idosos apontaram o nível de conhecimento que tinham sobre ela, além das dificuldades encontradas no processo de desenvolvimento do infográfico na ferramenta Easel.ly. Conforme pode ser observado na Figura 2, a maioria dos idosos não apresentou dificuldades no uso da ferramenta, atribuindo, em uma escala de 0 (zero) a 5 (cinco), uma escala de relevância entre 3 (três) e 5 (cinco). 
Em uma escala de 0 a 5, como você avalia o seu conhecimento do Easel.ly? 25 respostas

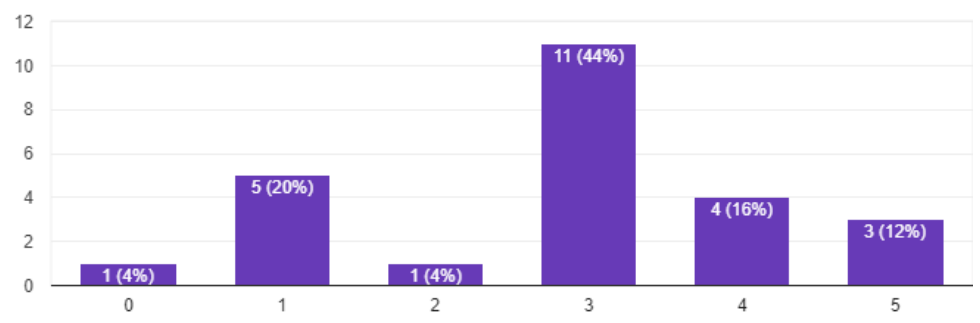

Fonte: Elaborada pelas autoras (2018).

A percepção desses alunos sobre o uso da ferramenta e construção dos infográficos pode ser visualizada nos trechos a seguir6: "Sim [tive dificuldades] mas, após ter o tutorial em mãos facilitou bastante" (Idoso 11); "Não [tive dificuldades]. As explicações em aula dadas pelas professoras e o material de apoio elaborado por elas está perfeito" (Idoso 20); "Nunca tinha feito um infográfico. Não tive dificuldades em fazer porque as professoras explicaram muito bem. Elas colocaram passo a passo muito bem elaborados, portanto fáceis de entender" (Idoso 23).

Como é possível perceber, os idosos tiveram algumas dificuldades no manuseio da ferramenta, mas o tutorial desenvolvido pelas professoras com explicações auxiliou no seu uso. Dessa forma, a partir da disponibilização de um tutorial sobre a ferramenta, os idosos sentiram-se mais confiantes e autônomos em construir e/ou concluir os seus infográficos nos momentos de aula, então realizados à distância.

Em relação ao idioma, foi apontado que a utilização da ferramenta em outra língua não dificultou o processo: "Seria mais interessante se fosse em português, mas em espanhol ajudou muito" (Idoso 12); "Não, pois algumas palavras em espanhol são parecidas em português e quando surgiu dúvida de uma palavra solicitei a tradução para a professora" (Idoso 18); "Não, eu acho que tudo é uma questão de usar a ferramenta e tentar se adaptar a ela" (Idoso 4).

Embora para a maioria dos alunos a língua não tenha dificultado, eles apresentaram receio em utilizar uma ferramenta em outra língua: "Eu pensei

6 Com vistas a preservar a identidade dos idosos participantes serão utilizados números de 1 a 25 para identificá-los. 
que iria dificultar, mas com as orientações das professoras não tive problemas" (Idoso 20); "um pouco, porque estamos acostumados a receber tudo mastigado" (Idoso 21); "Sim, simplesmente porque eu não sei nada de espanhol" (Idoso 25).

A realização de uma atividade com idosos por meio do uso de uma ferramenta em outra língua (não há uma versão em português disponível) foi uma grande preocupação ao longo do desenvolvimento da tarefa. Assim sendo, foi orientada a utilização da versão em espanhol e disponibilizado um tutorial com imagens e com explicações em português que, como pode ser observado, foi fundamental para o público em questão.

Os dados coletados apontaram que alguns idosos possuíam dificuldades no uso da ferramenta. No entanto, eles buscaram diferentes formas e meios para sanar as dúvidas com as professoras e construir os seus materiais digitais. Em relação às interações sociais e postagem dos materiais realizadas no AVA, foi possível observar a importância das mediações dos professores para instigar as trocas entre os participantes e, assim, possibilitar o desenvolvimento da autoria digital.

Apesar das dificuldades enfrentadas no processo, a construção dos infográficos demonstrou-se como uma oportunidade para que os idosos pudessem compartilhar as suas experiências, bem como divulgar as instituições em que realizam trabalho voluntário e/ou que recebem doações de diferentes tipos de materiais, roupas e alimentos. Alguns desses idosos, quando questionados se utilizariam esse recurso de outras formas ou para diferentes fins, demonstraram que possuem interesse em aprender mais sobre a ferramenta e que gostariam de utilizá-la novamente: "Sim. Vou tentar criar um infográfico mais objetivo às minhas funções" (Idoso 1); "Talvez, nos planejamentos das minhas viagens, já faço meus esquemas com roteiros e detalhes em caderno de anotações e sempre dá certo" (Idoso 16); "Sim, vou tentar fazer a árvore genealógica da minha família" (Idoso 18).

O uso da ferramenta para a construção de infográficos foi significativo para o desenvolvimento da autoria digital, contribuindo para minimizar a exclusão digital que ainda existe entre o público alvo. Por fim, finalizados os infográficos, os idosos participaram de uma exposição em um evento que ocorreu na mesma faculdade, em que é ofertado o curso de inclusão digital. Os idosos puderam expor as suas produções e divulgar o seu trabalho, possibilitando explorar o seu potencial criativo e a sua inserção na sociedade digital. 
O presente trabalho teve o intuito de analisar as contribuições da autoria digital, por meio de infográficos elaborados por idosos de um curso de inclusão digital. Para tanto, foi realizada uma pesquisa qualitativa e quantitativa com idosos participantes de um curso de inclusão digital, os quais possuíam diferentes níveis de conhecimento sobre as tecnologias digitais. Os resultados demonstram que os participantes obtiveram oportunidades para expressarem-se criativamente por meio da produção de conteúdo digital, a partir dos infográficos, desenvolvendo a autoria digital. Dessa forma, a pesquisa foi desenvolvida incluindo atividades práticas, abrangendo as necessidades de todos os participantes.

A partir dos dados coletados na pesquisa, foi possível observar o processo de autoria digital, dificuldades no uso da ferramenta Easel.ly e promover uma autoavaliação dos idosos sobre o processo de aprendizagem e produção. Entende-se que atividades como essa são fundamentais para que o idoso possa ver-se como um membro ativo da sociedade, bem como possa encontrar formas de compartilhar as suas atividades e experiências com outros idosos ou jovens, promovendo, de fato, a sua inclusão.

\section{OLDER ADULTS' DIGITAL AUTHORSHIP: THE PRODUCTION OF INFOGRAPHICS IN A DIGITAL INCLUSION COURSE}

abstract

The goal of this research is to analyze the possible contributions of digital authorship, through infographics of a group of older participants of a digital inclusion course. Population aging and the increasing use of digital technologies are a current reality. Thus, we noticed the need to propose situations that allow older adults to experience digital resources so that they can be included technologically. The research took qualitative and quantitative approaches. Twenty-five older adults took part in a digital inclusion project carried out at a public university in southern Brazil. For data collection, a questionnaire containing open and closed questions, participant observation and analysis of the built infographics were used. The participants' statements made it possible to observe an improvement in the self-esteem of the older adults due to the possibility of developing infographics through digital authorship. From the data analysis, it was also noted that, despite 
the difficulties about the use of a digital tool, most participants stated that they want to use the tool again. Such evidences indicate that the accomplishment of this type of activity can be an opportunity for social inclusion through digital inclusion.

keywords

Older Adults. Continuing Education. Digital Technology. Authorship. Learning.

referências

ALVARENGA, Glaucia Martins de Oliveira; DELFINO, Laís Lopes; SILVA, Laís dos Santos Vinholi; YASSUDA, Mônica Sanches; CACHIONI, Meire. Idosos e inclusão digital com tablet: uma revisão sistemática da literatura. Estudos Interdisciplinares sobre o EnveIhecimento, Porto Alegre, v. 23, n. 1, p. 125-142, 2018.

BARDIN, Laurence. Análise de conteúdo. 4. ed. Lisboa: Edições 70, 2010.

BEHAR, Patricia Alejandra; MACHADO, Leticia Rocha; RIBEIRO, Ana Carolina Ribeiro; EBELING, Larissa. Trabalho voluntário e inclusão digital: indicadores para uma qualidade de vida. In: TERRA, Newton Luiz; FERREIRA, Anderson Jackle; TACQUES, Claudia de Oliveira; MACHADO, Leticia Rocha (org.). Envelhecimento e suas múltiplas áreas do conhecimento. Porto Alegre: EDIPUCRS, 2010. p. 95-105.

BEZERRA, Carolina Cavalcanti; SERAFIM, Maria Lúcia. As gerações de infográficos comunicativos: propostas e possibilidades para a educação a distância. In: SOUSA, Robson Pequeno et al. (org.). Teorias e práticas em tecnologias educacionais. Campina Grande: EDUEPB, 2016. p. 99-122. Disponível em: http://books.scielo.org/id/fp86k. Acesso em: 15 maio 2018.

CENTRO INTERNACIONAL DE LONGEVIDADE BRASIL (ILC-BR). Envelhecimento ativo: um marco político em resposta à revolução da longevidade. Rio de Janeiro: ILC-BR, 2015. Disponível em: http://ilcbrazil.org/portugues/wpcontent/uploads/sites/4/2015/12/ Envelhecimento-Ativo-Um-Marco-Pol\%C3\%ADtico-ILC-Brasil_web.pdf. Acesso em: jan. 2017.

COSTA, Valéria Machado; TAROUCO, Liane Margarida Rockenbach. Infográfico: características, autoria e uso educacional. RENOTE: Revista Novas Tecnologias na Educação, Porto Alegre, v. 8, n. 3, p. 1-13, 2010. Disponível em: http://seer.ufrgs.br/ index.php/renote/article/view/18045/10633. Acesso em: 8 maio 2018.

DOLL, Johannes; MACHADO, Leticia Rocha; CACHIONI, Meire. O idoso e as novas tecnologias. In: FREITAS, Elizabete Viana et al. (ed.). Tratado de Geriatria e Gerontologia. 3. ed. Rio de Janeiro: Guanabara Koogan, 2016. p. 1604-1611.

FERREIRA, Anderson Jackle; GOULART, Denise. Convivendo em um mundo tecnológico. In: TERRA, Newton Luiz; BÓS, Ângelo J. G.; CASTILHOS, Nara (org.). Temas sobre envelhecimento ativo. Porto Alegre: EDIPUCRS, 2013. p. 103-109.

FOUCAULT, Michel. O que é um autor? Lisboa: Passagens, 2009.

INSTITUTO BRASILEIRO DE GEOGRAFIA E ESTATÍSTICA (IBGE). Síntese de indicadores sociais: uma análise das condições de vida da população brasileira. Rio de Janeiro: IBGE, 2017. (Estudos e Pesquisas. Informação Demográfica e Socioeconômica, n. 37). 
KACHAR, Vitória. Terceira idade e informática: aprender revelando possibilidades. São Paulo: Cortez, 2003.

LORETO, Elisa Sergi Gordilho; FERREIRA, Giselle Martins dos Santos. Desafios e possibilidades para a Inclusão Digital da Terceira Idade. Revista Eletrônica de Educação, São Carlos, v. 8, n. 2, p. 120-137, 2014. Disponível em: www.reveduc.ufscar.br/index. php/reveduc/article/download/736/329. Acesso em: 10 maio 2018.

MENEZES, Maria Eduarda de Lima. Tecnologias e mídias digitais no processo educativo e a autoria de alunos: limites, contribuições e possibilidades. 2013. 184 f. Dissertação (Mestrado em Educação) - Pontifícia Unniversidade Católica de São Paulo, São Paulo, 2013.

NEVES, Carmen Moreira de Castro. Pedagogia de autoria. Boletim Técnico do Senac, Rio de Janeiro, v. 31, n. 3. 2016. Disponível em: www.bts.senac.br/index.php/bts/ article/download/328/311. Acesso em: 6 maio 2018

ROCHA, Rosana Gonçales Oliveira; FARIA, João Roberto Gomes de; SALES, André Barros de; BRITO, Rita; AMARAL, Marília Abrahão; SALES, Márcia Barros de. Inclusão digital de pessoas idosas: um estudo de caso utilizando computadores desktop e tablets. RENOTE: Revista Novas Tecnologias na Educação, Porto Alegre, v. 14, n. 1, p. 1-11, 2016. Disponível em: http://seer.ufrgs.br/index.php/renote/article/view/67329. Acesso em: 8 maio 2018 